\title{
Comparison of Two Apnea Test Methods, Oxygen Insufflation and Continuous Positive Airway Pressure During Diagnosis of Brain Death: Final Report
}

\author{
Joanna Solek-Pastuszka', Jowita Biernawska ${ }^{1 *}$, Waldemar Iwańczuk ${ }^{2}$, Klaudyna Kojder $^{1}$, Kornel Chelstowski ${ }^{3}$,
} Romuald Bohatyrewicz ${ }^{1}$ and Marcin Sawicki ${ }^{4}$

(C) 2018 The Author(s)

\begin{abstract}
Introduction: Deterioration of the pulmonary function after the apnea test (AT) conducted with the classic oxygen insufflation AT (I-AT) is often observed during the brain death (BD) diagnosis procedure. In the present study, two AT methods were compared before a method is recommended for the currently revised Polish BD criteria.

Methods: Classic I-AT and continuous positive airway pressure AT (CPAP-AT) were performed in 60 intensive care unit patients. I-AT was performed at the end of two series of clinical tests, and approximately 1-1.5 h later, after BD was confirmed, a different method, CPAP-AT with $100 \% \mathrm{FiO}_{2}$ and CPAP value of $10 \mathrm{~cm} \mathrm{H}_{2} \mathrm{O}$ provided by a ventilator in CPAP mode was performed. The patients in I-AT and CPAP-AT groups were further divided into two subgroups: non-hypoxemic $(\mathrm{NH})$ with good lung function before $\mathrm{AT}\left(\mathrm{PaO}_{2} / \mathrm{FiO}_{2}\right.$ index $\left.\geq 200 \mathrm{mmHg}\right)$ and hypoxemic $(\mathrm{H})$ with poor lung function $\left(\mathrm{PaO}_{2} / \mathrm{FiO}_{2}\right.$ index $<200 \mathrm{mmHg}$. $\mathrm{PaO}_{2}$ and $\mathrm{PaCO}_{2}$ were recorded prior to I-AT and CPAP-AT at time-point one (T1), 5 min after each test at time-point two (T2), and after 10 min prior to the end of tests at time-point three (T3). The I-AT $\mathrm{NH}$ subgroup consisted of 50 patients, and CPAP-AT NH subgroup 43 patients. The I-AT H subgroup consisted of 10 patients, and the CPAP-AT H subgroup 17 patients.

Results: In the I-AT NH subgroup, a gradual decrease in $\mathrm{PaO}_{2} / \mathrm{FiO}_{2}$ was observed throughout the AT but not in the CPAP-AT NH subgroup. The $\mathrm{PaO}_{2} / \mathrm{FiO}_{2}$ ratio during the AT in the CPAP-AT H group was stable with a slight tendency to increase but not in the I-AT H group. During the first 5 min of the AT, the mean increase in $\mathrm{CO}_{2}$ was approximately $5 \mathrm{mmHg} / \mathrm{min}$. Most patients in all groups met the AT criteria after $5 \mathrm{~min}$ of the test.
\end{abstract}

Conclusions: The results from the study show that I-AT may compromise pulmonary function in some cases and is one of the reasons for the recommendation of a safer option, CPAP-AT, in the currently revised Polish BD criteria. During AT, the mean $\mathrm{CO}_{2}$ increase rate was $5 \mathrm{mmHg} / \mathrm{min}$, which, in most patients, would allow the test to be completed after just 5 min.

Keywords: Apnea test, Brain death, Brain death diagnosis, Continuous positive airway pressure

*Correspondence: lisienko@wp.pl

1 Department of Anaesthesiology and Intensive Care, Pomeranian Medical University in Szczecin, Unii Lubelskiej 1,71-252 Szczecin, Poland Full list of author information is available at the end of the article

\section{Background}

Polish brain death (BD) criteria are currently under review. They are generally similar to US and other European guidelines based on the recognition of irreversible catastrophic brain damage and two series of clinical 
examinations confirming brainstem areflexia and apnea $[1,2]$. In Poland, instrumental ancillary tests are needed when confounders are present and in children under 2 years of age. All national BD diagnosis guidelines are periodically reviewed, but despite many efforts, they have not been unified to date [1].

Current debates between medical practitioners in Poland cover many aspects, including the evolution of BD concepts [3] and the implementation of new diagnostic techniques such as computed tomography (CT) angiography and perfusion [4]. Practical aspects of clinical examinations including the apnea test (AT) in patients with poor lung function or extracorporeal membrane oxygenation support are extensively discussed [5].

The AT is one of the most important examinations during $\mathrm{BD}$ diagnosis and usually performed at the end of each of two series of clinical examinations. The most common, classical insufflation AT (I-AT) is currently recommended in Polish BD criteria published in 2007 [6]. According to the instructions, classic I-AT should be started in normoventilated patients with a $10-\mathrm{min}$ preoxygenation with $100 \%$ of $\mathrm{O}_{2}$ followed by blood collection to determine baseline arterial blood gas (ABG) [6]. Peripheral capillary $\mathrm{O}_{2}$ saturation and invasive blood pressure should be continuously monitored. After $10 \mathrm{~min}$, another blood sample should be collected to determine $\mathrm{ABG}$ and the patient should be reconnected to the ventilator with pretest settings. The test is considered valid if there are no spontaneous respirations despite the rise of $\mathrm{PaCO}_{2}$ above $60 \mathrm{mmHg}$ and over $20 \mathrm{mmHg}$ above the baseline, and the patient is declared apneic. In case of desaturation or circulatory disturbances, an alternative AT method, such as hypoventilation with $100 \% \mathrm{O}_{2}$, is recommended. To complete hypoventilation AT (H-AT) after preoxygenation, ventilator settings should be modified as follows: tidal volume and respiratory rate should be reduced to the minimal values at which the ventilator would not start backup apnea ventilation. These settings might differ depending on the type of ventilator. Positive endexpiratory pressure (PEEP) value should remain unchanged during this procedure. ABG levels should be monitored until test validity values are reached. During that period, patient's chest and ventilator monitor should be carefully observed to exclude any ventilatory efforts by the patient. Similar approach was previously described by Ahlawat et al. [7].

The second AT ends the diagnostic procedure, and afterward, according to Polish guidelines, a BD declaration protocol is signed by three doctors. One should be an anesthesiology and intensive care specialist, another a neurology or neurosurgery specialist, and the third with a specialty not defined by guidelines.
Classic I-AT may be potentially harmful, and several serious complications including severe hypoxemia, hemodynamic instability, pneumothorax, and even cardiac arrest have been reported [7-9]. In addition, according to unpublished information obtained from Polish transplant coordinators, I-ATs are often followed by the deterioration of pulmonary function. If this status is confirmed, it necessitates the recommendation of another AT option with less harmful impact on pulmonary function. All complications more likely occur in cases of serious lung damage when very fast desaturation is observed $[10,11]$. This may be caused by dramatic change of gas exchange conditions during the I-AT.

Usually, the patient is ventilated with a PEEP value of $5 \mathrm{~cm} \mathrm{H} \mathrm{H}_{2} \mathrm{O}$ and rarely higher than $12 \mathrm{~cm} \mathrm{H}_{2} \mathrm{O}$. Additional pressure generated during the ventilation cycle results in mean airway pressure up to of approximately $10-15 \mathrm{~cm}$ $\mathrm{H}_{2} \mathrm{O}$, which may keep the alveoli open even in moderately damaged lungs.

At the beginning of I-AT, after disconnection of the ventilator and placement of the insufflation catheter in the intubation tube, airway pressure rapidly falls close to $0 \mathrm{~cm} \mathrm{H}_{2} \mathrm{O}$. This may result in a rapid collapse of some alveoli; the others may collapse shortly after oxygen extraction to the pulmonary capillary vessels. Rapidly created pulmonary shunt may cause severe hypoxemia and result in a promptly preterm abortion of a test, which has often been reported [12]. Recruitment maneuvers and continuous positive airway pressure (CPAP) applied with some type of CPAP/PEEP valve [13], ventilator in CPAP mode, or with anesthesia machine circuit 11, may prevent such complications. Conversely, high CPAP/PEEP and recruitment may be theoretically risky and cause pneumothorax in some patients with pulmonary dysfunction, as suggested by van der Jagd et al. [14] in the commentary to the paper by Giani et al. [13].

In 2018, we published preliminary data from a multicenter trial based on 48 cases. In that study group, the ABG levels were mainly recorded at the beginning of AT and 10 min later at the end of AT, without an intermediate point at $5 \mathrm{~min}$. The primary results indicated the possibility of pulmonary deterioration after completion of I-ATP and showed that CPAP-AT could be a safer option for the AT [15].

In the current study, the two AT methods were compared and the hypothesis regarding the negative impact of I-AT on pulmonary function was verified using a larger group of patients prior to the planned recommendation of a safer alternative, CPAP-AT, for the currently revised Polish BD criteria [16]. 


\section{Methods}

The initial study plan for comparison of two AT methods was extended for the validation of CT angiography/ perfusion in BD diagnosis and approved by the Bioethical Committee of Pomeranian Medical University. Family consent was not obtained because, except for children, it is not required according to Polish law. In this study, we retrospectively analyzed prospectively collected data from a basic group of 76 adult patients declared brain dead in three intensive care units from 2014 to 2017. In 60 patients, approximately $1.5 \mathrm{~h}$ after I-AT followed by $\mathrm{BD}$ diagnosis, a different method, CPAP-AT, was performed. Sixteen patients were excluded from the basic group for various reasons. In three cases, classic I-AT was aborted due to rapid desaturation defined as a drop in $\mathrm{O}_{2}$ saturation below $90 \%$, after $1.5 \mathrm{~min}$ in the first case, $4 \mathrm{~min}$ in the second case, and $5 \mathrm{~min}$ in the third case. In addition, CPAP-AT was not attempted in eight patients because backup apnea ventilation could not be suspended when their ventilator was in the CPAP mode setting. In three cases, the documentation was incomplete, and in 2 cases the time span between I-AT and CPAP-AT was $12 \mathrm{~h}$, which could have resulted in a change of pulmonary function.

$\mathrm{PaO}_{2}$ and $\mathrm{PaCO}_{2}$ were recorded prior to I-AT and CPAP-AT (time-point one, T1), 5 min after each test (time-point two, T2) and after $10 \mathrm{~min}$ prior to the end of tests (time-point three, T3). Changes in $\mathrm{PaO}_{2} / \mathrm{FiO}_{2}$ and $\mathrm{PaCO}_{2}$ during the first 5 min of each AT (Delta 1, difference of values measured at T2 minus T1) and the subsequent 5 min of AT (Delta 2, difference of values measured at T3 minus T2) were analyzed. In addition, systolic blood pressure and heart rate were continuously monitored. Minor changes in blood pressure were managed by modification of vasopressor infusion.

During I-AT, the ventilator was disconnected and oxygen was delivered at a flow of $6 \mathrm{~L} / \mathrm{min}$ through the catheter inserted into the intubation tube. After BD was declared, approximately $1-1.5 \mathrm{~h}$ after the I-AT, a different method, CPAP-AT, was performed with a CPAP value of $10 \mathrm{~cm} \mathrm{H}_{2} \mathrm{O}$ delivered with the ventilator (Evita XL, Draeger, Germany) after 10 min of preoxygenation. ABG samples were collected at T1, T2, and T3 at the beginning of each AT. Recruitment maneuvers were generally not performed due to the possibility of decrease in cerebral blood flow which we considered potentially dangerous for the patients before a final BD diagnosis [17]. All I-ATs and CPAP-ATs were performed by experienced anesthesiologists and intensive care specialists. Brain blood perfusion tests such as digital subtraction angiography transcranial Doppler (TCD), CT angiography and CT perfusion were performed in the majority of patients. These tests were not only part of the BD declaration procedure but were also used to validate CT angiography and CT perfusion for the diagnosis of BD.

The time elapsed between the onset of brainstem areflexia and formal declaration of $\mathrm{BD}$ was $35.7 \pm 18.45 \mathrm{~h}$ (range $6-96 \mathrm{~h}$ ). Ventilator settings prior to I-AT included $\mathrm{FiO}_{2}$ of $0.3-1.0$ and PEEP of 3-15 cm $\mathrm{H}_{2} \mathrm{O}$. In the majority of cases, PEEP was $5 \mathrm{~cm} \mathrm{H}_{2} \mathrm{O}$.

The patients in each group (I-AT and CPAP-AT) were further divided into two subgroups: non-hypoxemic $(\mathrm{NH})$ with good lung function before the AT with $\mathrm{PaO}_{2} / \mathrm{FiO}_{2}$ index $\geq 200 \mathrm{mmHg}$, and hypoxemic $(\mathrm{H})$ with poor lung function with $\mathrm{PaO}_{2} / \mathrm{FiO}_{2}$ index $<200 \mathrm{mmHg}$. The I-AT NH subgroup consisted of 50 patients, and CPAP-AT NH subgroup 43 patients. The I-AT $\mathrm{H}$ subgroup consisted of 10 patients, and CPAP-AT $\mathrm{H}$ subgroup 17 patients. $\mathrm{PaO}_{2}$ and $\mathrm{PaCO}_{2}$ at time-points $\mathrm{T} 1, \mathrm{~T} 2$, and $\mathrm{T} 3$ were subsequently compared within these subgroups. Data were presented as mean \pm standard deviation (SD) and standard error (SE). Groups at time-points Delta 1 and Delta 2 were compared using the Wilcoxon test for pairs of measurements at statistical significance level $p<0.05$. Statistica 12.5PL software (StatSoft, Tulsa, OK, USA) was used for calculations and graph drawings.

\section{Results}

I-AT and CPAP-AT were completed in 60 patients without serious complications such as severe desaturation, cardiac arrhythmia, or pneumothorax. Among the 60 patients included in this study, $63.3 \%$ were males and the mean age was $52.3 \pm 13.26$ years. The most common causes of death were cerebrovascular accidents (63\%), traumatic brain injuries (25\%), anoxic injuries (6\%), and others (6\%). Cessation of cerebral perfusion based on TCD or aortic arch angiography was confirmed in 38 cases, and electroencephalographic silence was observed in one case. In 21 patients, ancillary brain blood perfusion tests were not performed due to technical or organizational difficulties; however, this did not affect BD declaration.

The time elapsed between the onset of brainstem areflexia and formal declaration of BD was $35.7 \pm 18.45 \mathrm{~h}$ (range 6-96 h). Ventilator settings prior to I-AT included $\mathrm{FiO}_{2}$ of $0.3-1.0$ and PEEP of 3-15 $\mathrm{cm} \mathrm{H}_{2} \mathrm{O}$; in the majority of cases, PEEP was $5 \mathrm{~cm} \mathrm{H}_{2} \mathrm{O}$.

In addition to gasometrical tests, hemodynamic changes during the AT were analyzed. Hemodynamic parameters of the AT are shown in Table 1.

\section{1. $\mathrm{PaO}_{2}$}

The results of both ATs in the NH subgroup are presented in Fig. 1. 
Table 1 Hemodynamic parameters during apnea test

\begin{tabular}{lcll}
\hline Group & $\begin{array}{l}\text { Heart rate (beats/ } \\
\mathbf{m i n})\end{array}$ & $\begin{array}{l}\text { Systolic BP } \\
(\mathbf{m m H g})\end{array}$ & $\begin{array}{l}\text { Diastolic BP } \\
(\mathbf{m m H g})\end{array}$ \\
\hline I-AT NH & $98 \pm 18$ & $142 \pm 25$ & $80 \pm 14$ \\
I-AT H & $100 \pm 23$ & $137 \pm 19$ & $78 \pm 12$ \\
CPAP-AT NH & $99 \pm 22$ & $138 \pm 26$ & $79 \pm 15$ \\
CPAP-AT H & $107 \pm 22$ & $127 \pm 17$ & $72 \pm 11$ \\
\hline
\end{tabular}

$B P$ Blood pressure, CPAP-AT H Continuous positive airway pressure apnea test in hypoxemic subgroup, CPAP-AT NH Continuous positive airway pressure apnea test in non-hypoxemic subgroup, I-ATH Insufflation apnea test in hypoxemic subgroup, I-AT NH Insufflation apnea test in non-hypoxemic subgroup

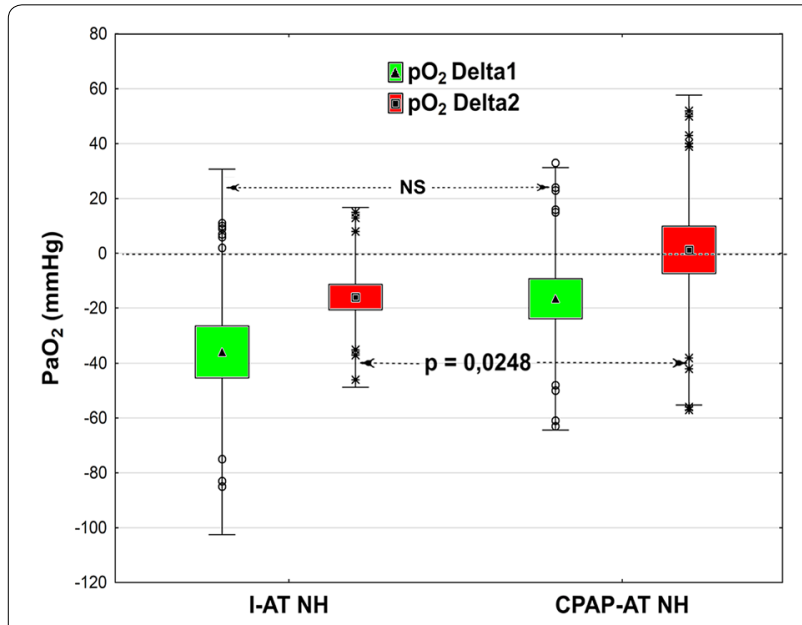

Fig. 1 Change in $\mathrm{PaO}_{2} / \mathrm{FiO}_{2}$ in the $\mathrm{NH}$ subgroup during the first 5 min of the AT (Delta $1=T 2-T 1$ ) and during subsequent 5 min (Delta $2=T 3-T 2)$. Box and whisker plots: data are represented as means (triangle or square in midpoint), SE (top and bottom of box) and SD (whiskers). Open circles or stars are outliers

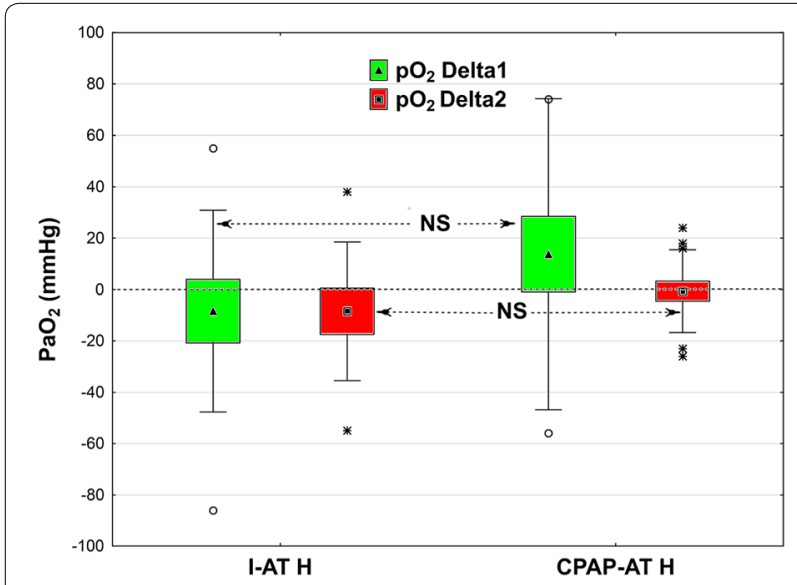

Fig. 2 Change in $\mathrm{PaO}_{2} / \mathrm{FiO}_{2}$ during the first 5 min of AT (Delta $1=\mathrm{T} 2-\mathrm{T} 1$ ) and during subsequent $5 \mathrm{~min}$ (Delta 2=T3_T2) in the two subgroups, I-AT H and CPAP-AT H. Box and whisker plots: data are represented as means (triangle or square in midpoint), SE (top and bottom of box) and SD (whiskers). Open circles or stars are outliers
In single cases, increasing $\mathrm{PaO}_{2}$ was observed during the AT in both groups. The results of both ATs in the $\mathrm{H}$ subgroup are presented in Fig. 2. In the I-AT $\mathrm{NH}$ subgroup, a gradual decrease in $\mathrm{PaO}_{2} / \mathrm{FiO}_{2}$ was observed throughout AT but not in the CPAP-AT $\mathrm{NH}$ subgroup.

2. $\mathrm{pCO}_{2}$

The mean increase in $\mathrm{CO}_{2}$ in the $\mathrm{NH}$ subgroup was approximately $5 \mathrm{mmHg} / \mathrm{min}$. The majority of patients in both subgroups after first 5 min of the test met the AT criteria; $50 \%$ slower increase in $\mathrm{CO}_{2}$ was observed during the next $5 \mathrm{~min}$ of the test. Results from the NH subgroups are presented in Fig. 3.

During the first $5 \mathrm{~min}$, the mean increase in $\mathrm{pCO}_{2}$ in the $\mathrm{H}$ subgroups (mean increase over $5 \mathrm{mmHg} \mathrm{CO}_{2} /$ min) was comparable to values in $\mathrm{NH}$ subgroups. Results from the H subgroups are presented in Fig. 4.

In all three cases in which I-AT or CPAP-AT could not be completed due to rapid desaturation, the ATs with H-AT method were successfully performed without complications and BD diagnosis based purely on clinical criteria was possible. Of the 76 patients, 40 became organ donors. In 36 cases, organs were not obtained due to medical contraindications or family refusal.

\section{Discussion}

The AT is the last clinical examination performed for the determination of death. It may be accompanied by severe desaturation and/or circulatory disturbances and therefore has to be aborted and modified, or in some cases, an additional instrumental confirmatory test has to be performed to complete the BD diagnosis [1]. Such complications were reported in 5\% of cases [18], which is close to the results obtained in the present study, and I-AT had to be stopped in 3 of 76 cases. The rate of aborted ATs could potentially have been reduced if recruitment maneuvers were performed in patients with poor pulmonary function, but these were not included in our protocols, either before or after the AT. When this research was planned, the prevailing opinion based on literature was that greater damages than benefits could result from using recruitment maneuvers in patients with CNS pathology. During the research, our opinion changed and therefore we currently recommend recruitment maneuvers, especially in the I-AT option.

Probable collapse of a part of alveoli during I-AT may become permanent, especially if recruitment maneuvers are not subsequently performed. This may have explained translocation of some patients from the $\mathrm{NH}$ to $\mathrm{H}$ 


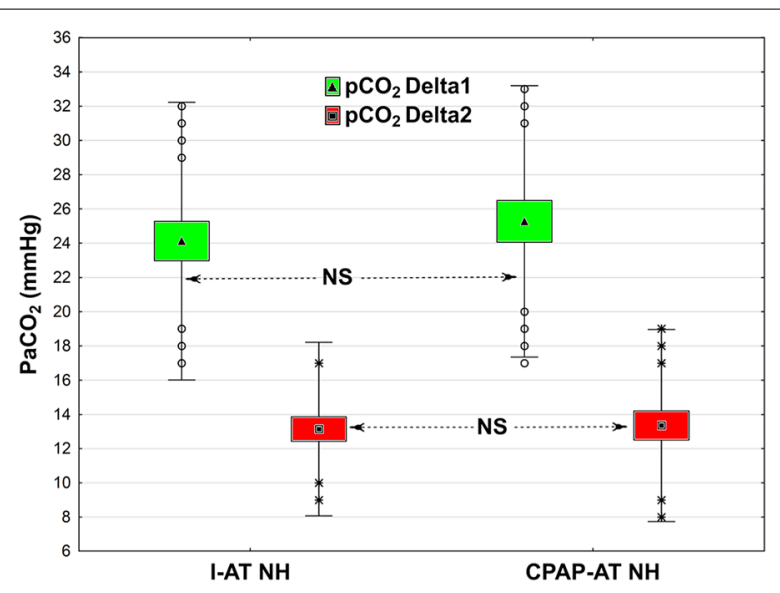

Fig. 3 Change in $\mathrm{PaCO}_{2}$ during the first 5 min of AT (Delta $1=T 2-T 1$ ) and during subsequent $5 \mathrm{~min}$ (Delta $2=\mathrm{T} 3-\mathrm{T} 2$ ) in the two subgroups, I-AT NH and CPAP-AT NH. Box and whisker plots: data are represented as means (triangle or square in midpoint), SE (top and bottom of box) and SD (whiskers). Open circles or stars are outliers

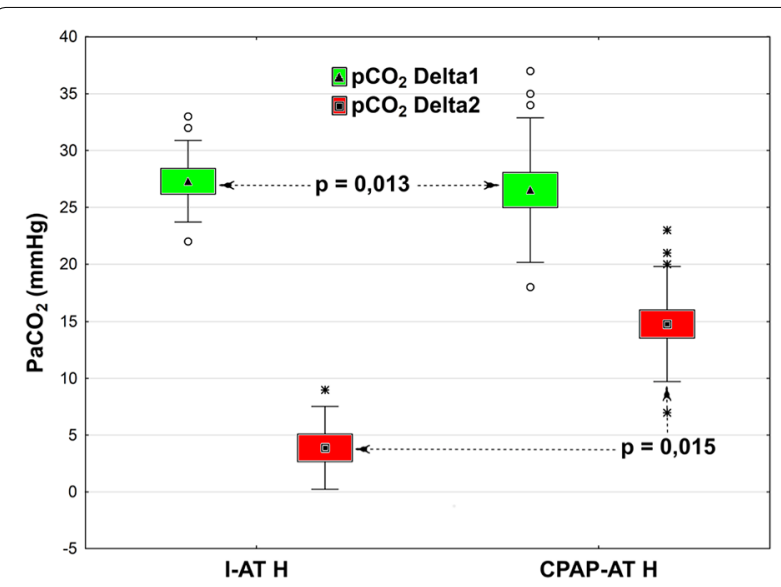

Fig. 4 Change in $\mathrm{PaCO}_{2}$ during the first 5 min of AT (Delta 1=T2_T1) and during subsequent 5 min (Delta 2=T3-T2) in the two subgroups, I-AT H and CPAP-AT H. Box and whisker plots: data are represented as means (triangle or square in midpoint), SE (top and bottom of box) and SD (whiskers). Open circles or stars are outliers

subgroup. Such phenomenon may not appear after I-AT if some type of 'intrinsic PEEP' was generated due to relatively big diameter of insufflation catheter or higher oxygen flow $[19,20]$.

In the I-AT NH subgroup, a gradual decrease in $\mathrm{PaO}_{2} /$ $\mathrm{FiO}_{2}$ was observed throughout AT but not in the CPAP-AT $\mathrm{NH}$ subgroup. Similar findings were presented by Levesque et al. and Kramer et al. [21, 22]. Despite the lack of significant differences between $\mathrm{PaO}_{2} / \mathrm{FiO}_{2}$ values at the beginning and end of the tests in our study, this phenomenon could be particularly important in clinical terms in hypoxemic patients in whom $\mathrm{PaO}_{2} / \mathrm{FiO}_{2}$ is $<200 \mathrm{mmHg}$ before the tests.
In the $\mathrm{H}$ subgroup, an increase in $\mathrm{PaO}_{2} /$ $\mathrm{FiO}_{2} \geq 200 \mathrm{mmHg}$ was also observed in single cases during CPAP-AT, which requires further analysis. We cannot exclude the possibility of passive recruitment of borderline alveoli due to steady CPAP during the test. The CPAP value of $10 \mathrm{~cm} \mathrm{H}_{2} \mathrm{O}$ could be close to, or sometimes higher than, mean airway pressure during ventilation and almost always higher than the PEEP value. Notably, the scatter of variables in the CPAP-AT H subgroup was considerable. This could be attributed to small sample size (17 cases) and differences in the severity of lung pathology. In patients with $\mathrm{PaO}_{2} / \mathrm{FiO}_{2}<200 \mathrm{mmHg}$ from the CPAP-AT group, aborting the test due to desaturation was not necessary. The use of this method may allow practitioners to avoid the necessity to use the ancillary tests in some cases during BD diagnosis. Conversely, this reduction of ancillary test number may not occur in Poland due to poor confidence of health care professionals and disagreement regarding $\mathrm{BD}$ diagnosis in some very active medical and religious authority groups. Polish physicians may feel more comfortable and safe if they could demonstrate the results of instrumental ancillary tests confirming BD diagnosis. Brain blood perfusion tests are considered the most evident for both sides of the discussion, the physicians and the relatives of the deceased. Obviously, regardless of the level of education, non-perfused tissue must be dead.

The rate of increase in $\mathrm{CO}_{2}$ was similar in both groups. During the first $5 \mathrm{~min}$ of the AT, the mean increase was approximately $5 \mathrm{mmHg} / \mathrm{min}$, which allowed the test to be considered positive even at this stage. Similar findings were presented by Kramer et al. [22]. During the subsequent $5 \mathrm{~min}$, a slower increase in $\mathrm{CO}_{2}$ was observed, but in the CPAP-AT $\mathrm{H}$ subgroup, this process was more dynamic (14.8 vs. $3.8 \mathrm{mmHg} / 5 \mathrm{~min}$.). Thus, when the desired $\mathrm{CO}_{2}$ level was not achieved after $5 \mathrm{~min}$ in the CPAP-AT $\mathrm{H}$ subgroup, the increase in $\mathrm{CO}_{2} / \mathrm{min}$ was faster, which allowed for shorter AT.

Findings from the present study are currently used for the revision of the AT procedure in the Polish Brain Death Criteria. We recommend the following three versions of AT: CPAP-AT as a test of first choice, hypoventilation option as a second choice, and I-AT as a third choice. In addition, we recommend first ABG analysis after $5 \mathrm{~min}$ and then observe a definitive increase in $\mathrm{PaCO}_{2}$ value until the criteria of test validity are reached. This is consistent with the opinion of Kramer et al., based on the data obtained at the same time, but in organizationally different medical circumstances, that performance of ABGs at regular intervals shortens the AT duration and may avoid excessive $\mathrm{pH}$ reduction and subsequent hemodynamic effects [22]. We aborted the test in three cases due to hypoxemia resulting in failure rate 
similar to that reported by Lévesque and Kramer [21, 22]. However, we also noticed that H-AT may be a rescue option if AT cannot be completed with the other methods for any reason. This rarely mentioned option may circumvent the necessity to use ancillary tests which might be difficult to perform in unstable patients.

\section{Conclusions}

The results from the present study show that I-AT may compromise pulmonary function in some cases, and this may be one of the reasons for the recommendation of a safer option, CPAP-AT, in the currently revised Polish $\mathrm{BD}$ criteria. The mean $\mathrm{CO}_{2}$ increase rate during AT was $5 \mathrm{mmHg} / \mathrm{min}$, which in most patients would allow the test to be completed after just $5 \mathrm{~min}$.

\begin{abstract}
Abbreviations
BD: Brain death; AT: Apnea test; I-AT: Insufflation apnea test; H-AT: Hypoventilation apnea test; $\mathrm{NH}$ : Non-hypoxemic; $\mathrm{H}$ : Hypoxemic; $\mathrm{PaCO}_{2}$ : Arterial carbon dioxide tension; PEEP: Positive end-expiratory pressure; CPAP: Continuous positive airway pressure; CPAP-AT: Continuous positive airway pressure AT; ABG: Arterial blood gas; $\mathrm{SpO}_{2}$ : Peripheral capillary $\mathrm{O}_{2}$ saturation; $\mathrm{FiO}_{2}$ : Fractional inspired oxygen; $\mathrm{PaO}_{2} / \mathrm{FiO}_{2}$ : Ratio of arterial oxygen tension $\left(\mathrm{PaO}_{2}\right)$ to $\mathrm{FiO}_{2} ; \mathrm{SE}$ : Standard error; SD: Standard deviation.
\end{abstract}

\section{Authors' Contributions}

JS-P participated in study design and performed data collection. JB, MS, WI and RB participated in study design. KK performed data collection. KC performed primary data analysis. All authors participated in manuscript preparation and read and approved the final manuscript.

\begin{abstract}
Author details
1 Department of Anaesthesiology and Intensive Care, Pomeranian Medical University in Szczecin, Unii Lubelskiej 1, 71-252 Szczecin, Poland. ${ }^{2}$ Department of Anaesthesiology and Intensive Therapy, Regional Hospital in Kalisz, 62-800 Kalisz, Poland. ${ }^{3}$ Department of Laboratory Diagnostics, Pomeranian Medical University in Szczecin, Al. Powstańców Wlkp. 72j, 70-111 Szczecin, Poland. ${ }^{4}$ Department of Diagnostic Imaging and Interventional Radiology, Pomeranian Medical University in Szczecin, Unii Lubelskiej 1, 71-252 Szczecin, Poland.
\end{abstract}

\section{Source of Support}

No funding.

\section{Compliance with Ethical Standards}

\section{Conflict of interest}

The authors declare that they have no conflict of interest.

\section{Clinical Trial Registration}

ClinicalTrials.gov PRS. Date of registration 13 September 2017; Retrospectively registered. NCT03281993. https://clinicaltrials.gov/ct2/show/NCT0328199 3 ? spons=Pomeranian+Medical+University + Szczecin\&draw $=2 \&$ rank $=6$.

\section{Availability of Data and Materials}

All datasets analyzed during the current study are available from the corresponding author on reasonable request.

\section{Ethics Approval and Consent to Participate}

The study was approved by the Bioethical Committee of the Pomeranian Medical University.

\section{Open Access}

This article is distributed under the terms of the Creative Commons Attribution 4.0 International License (http://creativecommons.org/licenses/by/4.0/), which permits unrestricted use, distribution, and reproduction in any medium, provided you give appropriate credit to the original author(s) and the source, provide a link to the Creative Commons license, and indicate if changes were made.

Published online: 12 September 2018

\section{References}

1. Citerio G, Crippa IA, Bronco A, Vargiolu A, Smith M. Variability in brain death determination in Europe: looking for a solution. Neurocrit Care. 2014;21(3):376-82.

2. Wijdicks EF, Varelas PN, Gronseth GS, Greer DM. American Academy of, $\mathrm{N}$. Evidence-based guideline update: determining brain death in adults: report of the Quality Standards Subcommittee of the American Academy of Neurology. Neurology. 2010;74(23):1911-8.

3. Pabisiak K. Brain death criteria formulated for transplantation purposes: fact or myth? Anaesthesiol Intensive Ther. 2016;48(2):142-5.

4. Sawicki M, Sołek-Pastuszka J, Chamier-Ciemińska K, et al. Computed tomography perfusion is a useful adjunct to computed tomography angiography in the diagnosis of brain death. Clin Neuroradiol. 2017. https:// doi.org/10.1007/s00062-017-0631-7.

5. Saucha W, Solek-Pastuszka J, Bohatyrewicz R, Knapik P. Apnea test in the determination of brain death in patients treated with extracorporeal membrane oxygenation (ECMO). Anaesthesiol Intensive Ther. 2015;47(4):368-71.

6. Bohatyrewicz R, Nestorowicz A, Kusza K. Commentary on diagnosis procedures of brain death. Anestezjol Intens Ter. 2008;40(2):114-6.

7. Ahlawat A, Carandang R, Heard SO, Muehlschlegel S. The modified apnea test during brain death determination: an alternative in patients with hypoxia. J Intensive Care Med. 2016:31(1):66-9.

8. Saposnik G, Rizzo G, Vega A, Sabbatiello R, Deluca JL. Problems associated with the apnea test in the diagnosis of brain death. Neurol India. 2004;52(3):342-5

9. Goudreau JL, Wijdicks EF, Emery SF. Complications during apnea testing in the determination of brain death: predisposing factors. Neurology. 2000;55(7):1045-8.

10. Hocker S, Whalen F, Wijdicks EF. Apnea testing for brain death in severe acute respiratory distress syndrome: a possible solution. Neurocrit Care. 2014;20(2):298-300.

11. Shrestha GS, Shrestha PS, Acharya SP, et al. Apnea testing with continuous positive airway pressure for the diagnosis of brain death in a patient with poor baseline oxygenation status. Indian J Crit Care Med. 2014;18(5):331-3.

12. Datar S, Fugate J, Rabinstein A, Couillard P, Wijdicks EF. Completing the apnea test: decline in complications. Neurocrit Care. 2014;21(3):392-6.

13. Giani M, Scaravilli V, Colombo SM, et al. Apnea test during brain death assessment in mechanically ventilated and ECMO patients. Intensive Care Med. 2016;42(1):72-81.

14. van der Jagt $M$, Lin MS, Briegel J. Optimizing apnea testing to determine brain death. Intensive Care Med. 2016;42(1):117-8.

15. Solek-Pastuszka J, Sawicki M, Iwanczuk W, et al. Apnea testing using the oxygen insufflation method for diagnosis of brain death may compromise pulmonary function. J Crit Care. 2017;44:175-8.

16. Solek-Pastuszka J, Saucha W, Iwanczuk W, Bohatyrewicz R. Evolution of apnoea test in brain death diagnostics. Anaesthesiol Intensive Ther. 2015;47(4):363-7.

17. Bein $T$, Kuhr $L P$, Bele $S$, et al. Lung recruitment maneuver in patients with cerebral injury: effects on intracranial pressure and cerebral metabolism. Intensive Care Med. 2002;28(5):554-8.

18. Yee AH, Mandrekar J, Rabinstein AA, Wijdicks EF. Predictors of apnea test failure during brain death determination. Neurocrit Care. 2010;12(3):352-5 
19. Denny JT, Denny JE. Novel configuration of laryngeal mask airway. Int J Health Sci (Qassim). 2014;8(4):420-2.

20. Henry NR, Marshall SG. Apnea testing: the effects of insufflation catheter size and flow on pressure and volume in a test lung. Respir Care. 2014:59(3):406-10.

21. Lévesque S, Lessard MR, Nicole PC, et al. Efficacy of a T-piece system and a continuous positive airway pressure system for apnea testing in the diagnosis of brain death. Crit Care Med. 2006;34(8):2213-6.
22. Kramer AH, Couillard P, Bader R, et al. Prevention of hypoxemia during apnea testing: a comparison of oxygen insufflation and continuous positive airway pressure. Neurocrit Care. 2017;27(1):60-7. 